\title{
Hydroboration of Substituted Cyclopropane: A Density Functional Theory Study
}

\author{
Satya Prakash Singh ${ }^{1}$ and Pompozhi Protasis Thankachan ${ }^{2}$ \\ ${ }^{1}$ Department of Chemical Sciences, Indian Institute of Science Education and Research, Knowledge City, Sector 81, Mohali, \\ Panjab 140306, India \\ ${ }^{2}$ Indian Institute of Technology Roorkee, Roorkee 247667, India
}

Correspondence should be addressed to Satya Prakash Singh; satyapiit@gmail.com

Received 30 April 2014; Accepted 1 June 2014; Published 18 August 2014

Academic Editor: Daniel Glossman-Mitnik

Copyright (c) 2014 S. P. Singh and P. P. Thankachan. This is an open access article distributed under the Creative Commons Attribution License, which permits unrestricted use, distribution, and reproduction in any medium, provided the original work is properly cited.

The hydroboration of substituted cyclopropanes has been investigated using the B3LYP density functional method employing 6$31 \mathrm{G}^{* *}$ basis set. Borane moiety approaching the cyclopropane ring has been reported. It is shown that the reaction proceeds via a three-centered, "loose" and "tight," transition states when boron added to the cyclopropane across a bond to a substituents. Single point calculations at higher levels of theory were also performed at the geometries optimized at the B3LYP level, but only slight changes in the barriers were observed. Structural parameters for the transition state are also reported.

\section{Introduction}

Hydroboration of substituted alkenes has been investigated theoretically and experimentally. Brown and Zweifel [1] have shown that the hydroboration of alkyl substituted olefins yields the anti-Markownikoff addition product predominantly and that addition takes place predominantly at $\beta$-carbon atom. For monosubstituted olefins, 93-94\% of borane addition takes place at the terminal carbon atom. For di- and trisubstituted olefins the preference for the antiMarkownikoff product is $98-99 \%$. They have also observed steric and electronic effects in the case of trans-2-pentene.

When electron withdrawing groups are attached to the alkene preferential formation of the Markownikoff addition products has been reported. Phillips and Stone [2] have shown that borane adds to 1,1,1-trifluoropropene giving the Markownikoff product with $87-92 \%$ selectivity in appropriate solvents. Graham et al. [3] have carried out studies on the substituent effect in hydroboration of propylene and cyanoethylene using the partial retention of diatomic differential overlap (PRDDO) method with application of linear synchronous transits (LSTs) and orthogonal optimizations to construct the reaction pathways for the Markownikoff and anti-Markownikoff addition of borane to propylene and cyanoethylene. Villiers and Ephritikhine [4] have carried out the borane-catalysed hydroboration of substituted alkenes by lithium borohydride or sodium borohydride. They have shown the unusual order of decreasing reactivity: tetramethylethylene $>$ 1-methylcyclohexene > cyclohexene. $\mathrm{Xu}$ et al. [5] theoretically studied the hydroboration of disilenes with borane. They investigated the reaction mechanism exhaustively and found the mechanism for hydroboration of disilenes to be interestingly different from that proposed for hydroboration of alkenes.

We have theoretically investigated the hydroboration of cyclopropane [6] in which the borane moiety was situated along the plane of cyclopropane ring. After that the possibility of borane moiety perpendicular to cyclopropane ring has been reported [7] at different method and basis set. The reaction is similar to hydroboration of cyclopropane, that is, hydroalumination of cyclopropane with alane $\left(\mathrm{AlH}_{3}\right)$ [8] reported. In this paper we present our computational studies on the reactions of $\mathrm{BH}_{3}$ with cyclopropane in which the hydrogen atom is replaced with six different kinds of substituents $\left(-\mathrm{F},-\mathrm{Cl},-\mathrm{CN},-\mathrm{NC},-\mathrm{CH}_{3}\right.$, and $\left.-\left(\mathrm{CH}_{3}\right)_{2}\right)$ at DFT level of theory using $6-31 \mathrm{G}^{* *}$ basis set in each case. The main 


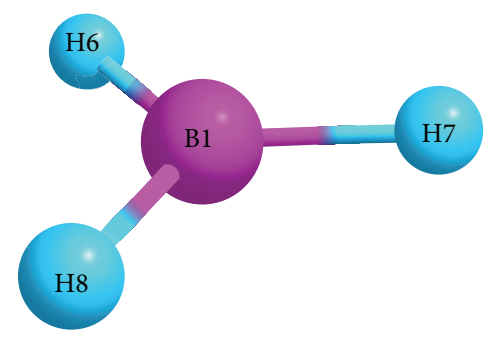

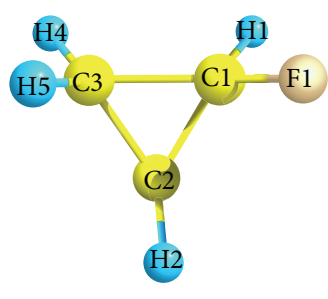

$\mathrm{C}_{3} \mathrm{H}_{5} \mathrm{~F}$

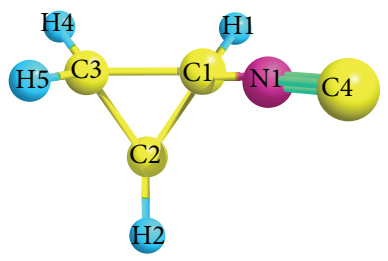

$\mathrm{C}_{3} \mathrm{H}_{5} \mathrm{NC}$

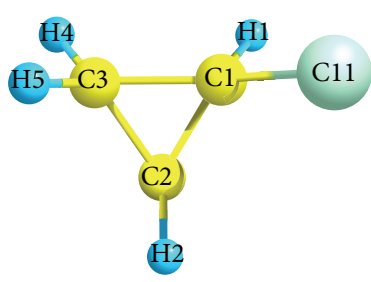

$\mathrm{C}_{3} \mathrm{H}_{5} \mathrm{Cl}$

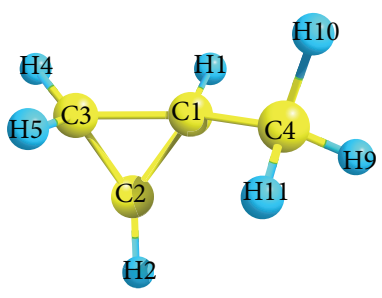

$\mathrm{C}_{3} \mathrm{H}_{5} \mathrm{CH}_{3}$

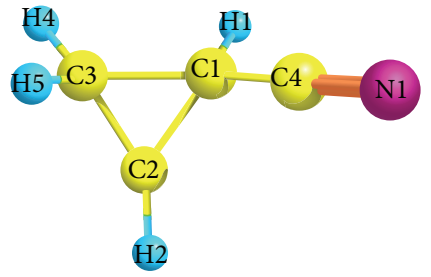

$\mathrm{C}_{3} \mathrm{H}_{5} \mathrm{CN}$

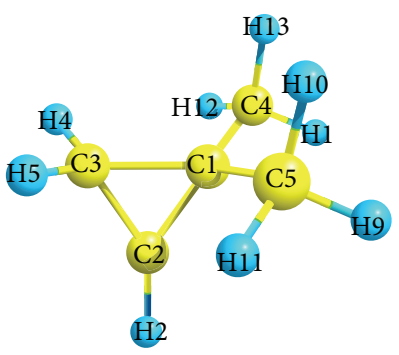

$\mathrm{C}_{3} \mathrm{H}_{4}\left(\mathrm{CH}_{3}\right)_{2}$

FIGURE 1: Optimized geometries of borane $\left(\mathrm{BH}_{3}\right)$ and six kinds of substituted cyclopropane at B3LYP/6-31G ${ }^{* *}$ level.

goal of work is to study the feasibility of reactions. Effect of substituents on the reaction mechanism and on energetics is investigated (see Supplementary Material available online at http://dx.doi.org/10.1155/2014/427396), and some calculations at higher levels of theory are also included.

\section{Computational Methods}

Optimization of all the geometries of stationary structures involved in the reaction was carried out using $6-31 \mathrm{G}^{* *}$ basis set at DFT/B3LYP [9] level using Gaussian $98 \mathrm{~W}$ software package [10]. The nature of each stationary point was probed by frequency calculations. Single point calculations at the DFT optimized geometry at higher ab initio levels of theory have also been performed. Single point calculations were done at CCSD, CCSD(T) [11-15], QCISD, QCISD(T) [15], MP2 [16-20], and MP4D [21] levels.

\section{Results and Discussion}

Six substituted cyclopropanes (Figure 1), namely, $\mathrm{C}_{3} \mathrm{H}_{5} \mathrm{~F}$, $\mathrm{C}_{3} \mathrm{H}_{5} \mathrm{Cl}, \mathrm{C}_{3} \mathrm{H}_{5} \mathrm{CN}, \mathrm{C}_{3} \mathrm{H}_{5} \mathrm{NC}, \mathrm{C}_{3} \mathrm{H}_{5}\left(\mathrm{CH}_{3}\right)$, and $\mathrm{C}_{3} \mathrm{H}_{4}\left(\mathrm{CH}_{3}\right)_{2}$, were chosen for the study of their reaction with borane. Addition of $\mathrm{BH}_{3}$ across bonds adjacent to the substituted atom has been studied. The structures of all the reactants were optimized at the $\mathrm{B} 3 \mathrm{LYP} / 6-31 \mathrm{G}^{* *}$ level and are shown in Figure 1. Here we have discussed the results of fluorocyclopropane and the result of other substituted cyclopropanes furnished in Supplementary Material.

There are two possibilities to be considered in connection with each substituted cyclopropane: first with the carbon atom bearing substituents denoted by $\mathrm{Cl}$, addition takes place across the $\mathrm{Cl}-\mathrm{C} 3$ bond and second addition takes place across the $\mathrm{C} 2-\mathrm{C} 3$ bond.

Optimization led to two types of transition states. In one case the $\mathrm{BH}_{3}$ group is closer to the ring ("tight" TS) and is on the side opposite the fluorine, whereas in the other the $\mathrm{BH}_{3}$ group is somewhat farther ("loose" TS) and on the side of the fluorine. The $\mathrm{BH}_{3}$ group has lost its planarity in both, but the distortion from planarity is more pronounced in the first case. These transition states are shown in Figure 2. IRC calculations from the transition states obtained show that the pathways through the transition states go towards the anti-Markownikoff and Markownikoff products, respectively. Figures 3 and 4 show the IRCs in these two cases.

On the other hand in the case of 1-chlorocyclopropane, we obtain both "tight" and "loose" transition states but in this case the path through the "tight" transition state leads to the 


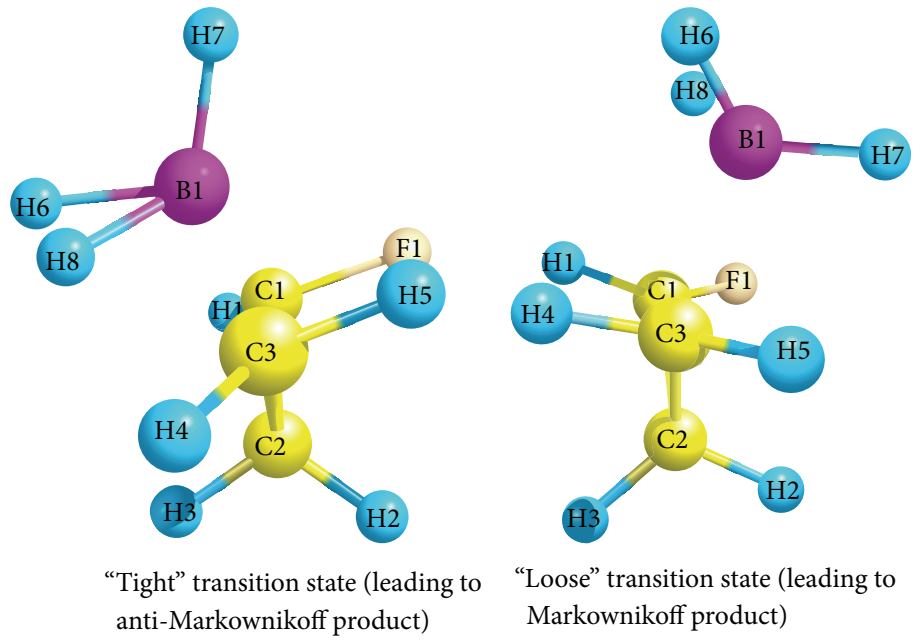

FIGURE 2: Transition states optimized at B3LYP/6-31G ${ }^{* *}$ in the case of 1-fluorocyclopropane along the plane of cyclopropane ring.

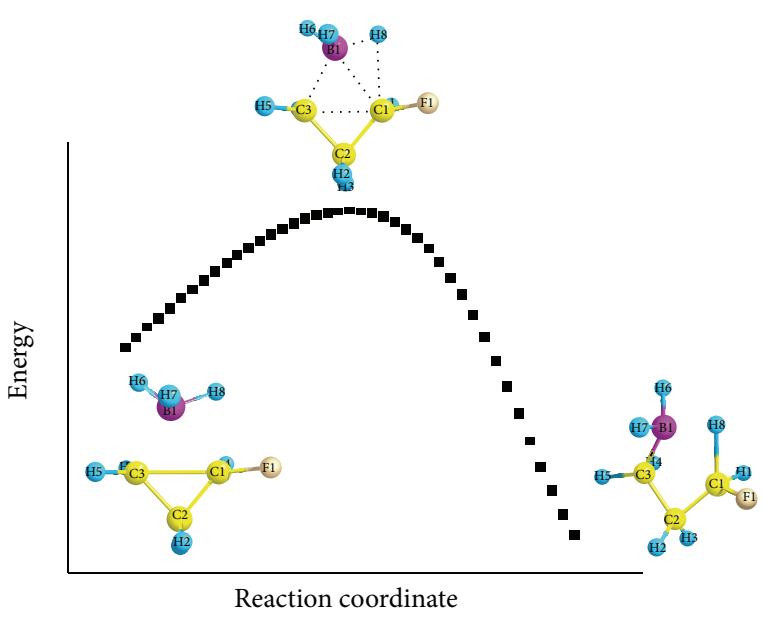

FIGURE 3: IRC plot for the loose transition state for the addition of borane to 1-fluorocyclopropane along the plane of cyclopropane ring.

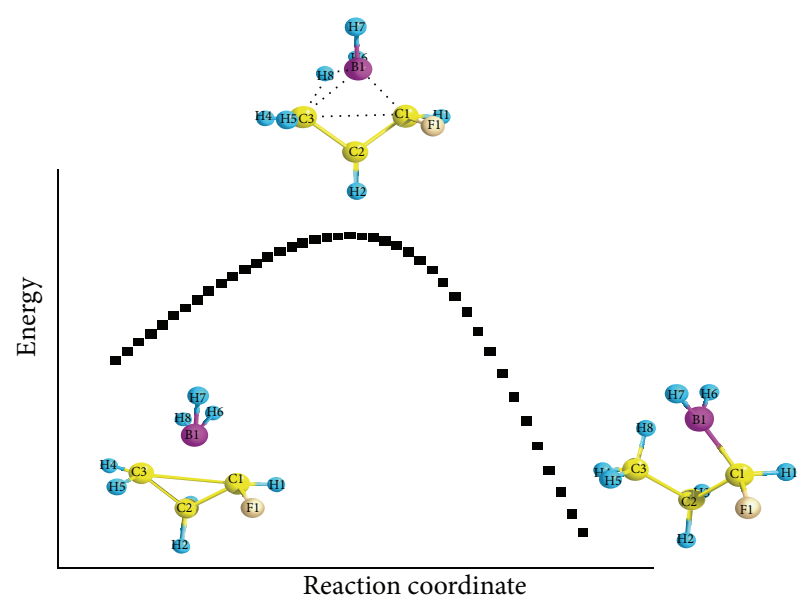

FIGURE 4: IRC plot for the tight transition state for the addition of borane to 1-fluorocyclopropane along the plane of cyclopropane ring.
Markownikoff product and the path through the "loose" transition state leads to the anti-Markownikoff product. Of the other substituted cyclopropanes studied it is found that cyano and isocyano cyclopropanes behave like chlorocyclopropane, while methyl and 1,1-dimethyl cyclopropanes behave like fluorocyclopropane in this respect (see the Supplementary Material).

For each of the substituted cyclopropanes, the structures of the transition structures at the B3LYP/6-31G ${ }^{* *}$ level were optimized. The "loose" transition state is preceded by an intermediate complex, while the "tight" transition state is apparently not. The structures of the complexes, "loose" transition structures, and products are shown in Figure S1 (Supplementary Material) and are denoted by LM-CX, TS, and LM, respectively. "LM" stands for local minimum on potential energy surface, "CX" stands for complex, and "TS" stands for transition state. The selected optimized structural parameters for these are shown in Table 1(a).

It is seen that the $\mathrm{C} 1-\mathrm{B} 1$ and $\mathrm{C} 3-\mathrm{B} 1$ distances found in the complexes are significantly longer in the case of all substituted cyclopropanes compared to the unsubstituted case; for example, in case of fluoro substitution the C1-B1 and C3-B1 distances are 3.094 and $2.922 \AA$ against $2.905 \AA$ in unsubstituted case pointing to weaker complexation. In the complex with $-\mathrm{F},-\mathrm{Cl},-\mathrm{CN}$, and $-\mathrm{NC}$ substituted cyclopropanes, the boron is nearly symmetrically disposed with respect to $\mathrm{C} 1$ and $\mathrm{C} 3$ (Figure S1) whereas in the case of methyl-substituted compounds (Figure S1) there is pronounced asymmetry, probably due to increased steric effects.

The $\mathrm{C} 1-\mathrm{C} 3$ distance in the "loose" transition structure for the reaction between cyclopropane and $\mathrm{BH}_{3}$ is $1.994 \AA$. In case of substitutions by $-\mathrm{F},-\mathrm{Cl},-\mathrm{CN}$, and $-\mathrm{NC}$ this distance is less than this value but in the methyl and dimethyl case it is greater, pointing to a weaker $\mathrm{Cl}-\mathrm{C} 3$ bond in these cases.

In the case of unsubstituted cyclopropane, in the transition state the $\mathrm{C} 1-\mathrm{B} 1$ distance is greater than C3-B1 (see Table 1(a)) and both are equal in the complex, indicating 
TABLE 1: (a) B3LYP/6-31G ${ }^{* *}$ optimized structural parameters (units in $\AA$ for bond length) for the -F substituted cyclopropanes, intermediate complexes (LM-CX), "loose" transition structures (TS), and products (LM) along the plane of cyclopropane ring. (b) B3LYP/6$31 \mathrm{G}^{* *}$ optimized structural parameters (units in $\AA$ for bond length and in degree for angle) for the "tight" transition structures (TS) and products (LM) along the plane of cyclopropane ring.

(a)

\begin{tabular}{lcccc}
\hline & $\mathrm{C} 1-\mathrm{C} 3$ & $\mathrm{C} 1-\mathrm{B} 1$ & $\mathrm{C} 3-\mathrm{B} 1$ & $\mathrm{~B} 1-\mathrm{H} 8$ \\
\hline $\mathrm{C}_{3} \mathrm{H}_{5} \mathrm{~F}$ & 1.493 & - & - & - \\
$\mathrm{LM}-\mathrm{CX} 1$ & 1.506 & 3.094 & 2.922 & 1.190 \\
$\mathrm{TS} 1$ & 1.912 & 1.991 & 1.829 & 1.209 \\
$\mathrm{LM} 1$ & 2.529 & 3.263 & 1.559 & 2.955 \\
$\mathrm{C}_{3} \mathrm{H}_{5} \mathrm{Cl}$ & 1.498 & - & - & - \\
$\mathrm{LM}-\mathrm{CX} 2$ & 1.505 & 3.350 & 3.141 & 1.190 \\
$\mathrm{TS} 2$ & 1.893 & 1.883 & 1.929 & 1.206 \\
$\mathrm{LM} 2$ & 2.498 & 1.565 & 3.417 & 3.166 \\
$\mathrm{C}_{3} \mathrm{H}_{5} \mathrm{CN}$ & 1.522 & - & - & - \\
$\mathrm{LM}-\mathrm{CX} 3$ & 1.528 & 3.325 & 3.209 & 1.190 \\
$\mathrm{TS} 3$ & 1.958 & 1.863 & 1.989 & 1.206 \\
$\mathrm{LM} 3$ & 2.546 & 1.590 & 3.231 & 2.914 \\
$\mathrm{C}_{3} \mathrm{H}_{5} \mathrm{NC}$ & 1.512 & - & - & - \\
$\mathrm{LM} \mathrm{CX} 4$ & 1.519 & 3.309 & 3.127 & 1.190 \\
$\mathrm{TS} 4$ & 1.947 & 1.926 & 1.910 & 1.207 \\
$\mathrm{LM} 4$ & 2.532 & 1.592 & 3.273 & 2.970 \\
$\mathrm{C}_{3} \mathrm{H}_{5} \mathrm{CH} H_{3}$ & 1.509 & - & - & - \\
$\mathrm{LM}-\mathrm{CX} 5$ & 1.522 & 3.166 & 2.894 & 1.191 \\
$\mathrm{TS} 5$ & 2.012 & 1.767 & 2.042 & 1.215 \\
$\mathrm{LM}_{5}$ & 2.580 & 3.303 & 1.558 & 2.960 \\
$\mathrm{C}_{3} \mathrm{H}_{4}\left(\mathrm{CH}_{3}\right)_{2}$ & 1.511 & - & - & - \\
$\mathrm{LM}-\mathrm{CX} 6$ & 1.519 & 3.493 & 2.942 & 1.192 \\
$\mathrm{TS} 6$ & 2.040 & 2.216 & 1.764 & 1.216 \\
$\mathrm{LM}_{6}$ & 2.591 & 3.304 & 1.558 & 2.915 \\
\hline
\end{tabular}

(b)

\begin{tabular}{ccccc}
\hline & C1-C3 & C1-B1 & C3-B1 & B1-H8 \\
\hline $\mathrm{C}_{3} \mathrm{H}_{5} \mathrm{~F}$ & & & & \\
$\mathrm{TS} 7$ & 2.251 & 1.620 & 1.759 & 1.264 \\
$\mathrm{LM} 7$ & 2.515 & 1.572 & 3.430 & 3.186 \\
$\mathrm{C}_{3} \mathrm{H}_{5} \mathrm{Cl}$ & & & & \\
$\mathrm{TS} 8$ & 2.293 & 1.809 & 1.609 & 1.266 \\
$\mathrm{LM} 8$ & 2.522 & 3.247 & 1.560 & 2.954 \\
$\mathrm{C}_{3} \mathrm{H}_{5} \mathrm{CN}$ & & & & \\
$\mathrm{TS} 9$ & 2.310 & 1.841 & 1.605 & 1.276 \\
$\mathrm{LM} 9$ & 2.546 & 3.261 & 1.561 & 2.930 \\
$\mathrm{C}_{3} \mathrm{H}_{5} \mathrm{NC}$ & & & & \\
$\mathrm{TS} 10$ & 2.309 & 1.837 & 1.606 & 1.267 \\
$\mathrm{LM} 10$ & 2.535 & 3.257 & 1.561 & 2.929 \\
$\mathrm{C}_{3} \mathrm{H}_{5} \mathrm{CH} \mathrm{H}_{3}$ & & & & \\
$\mathrm{TS} 11$ & 2.278 & 1.761 & 1.622 & 1.266 \\
$\mathrm{LM} 11$ & 2.579 & 1.558 & 3.272 & 2.971 \\
$\left.\mathrm{C}_{3} \mathrm{H}_{4}(\mathrm{CH})_{3}\right)_{2}$ & & & & \\
$\mathrm{TS} 12$ & 2.040 & 2.216 & 1.764 & 1.216 \\
$\mathrm{LM}_{12}$ & 2.591 & 1.566 & 3.211 & 2.894 \\
\hline
\end{tabular}

the tendency of "B1" to bond to "C3." In the substituted cases, the complexes themselves are unsymmetrical, with C1$\mathrm{B} 1$ distances being longer than the $\mathrm{C} 3-\mathrm{B} 1$ distances in all cases. However the "loose" transition state that follows this situation continues only in cases of $-\mathrm{F},-\mathrm{CH}_{3}$, and $-\left(\mathrm{CH}_{3}\right)_{2}$ substituents, whereas with $-\mathrm{Cl},-\mathrm{CN}$, and $-\mathrm{NC}$ in the TS, B1 is closer to "C1" suggesting that in these cases the "loose" transition state leads to the Markownikoff product whereas with $-\mathrm{F},-\mathrm{CH}_{3}$, and $-\left(\mathrm{CH}_{3}\right)_{2}$ these "loose" transition states lead to the anti-Markownikoff product.

The selected geometrical parameters for the "tight" transition structures are shown in Table 1(b). In these the C1C3 distances are greater than in the corresponding "loose" transition structures whereas the $\mathrm{C} 1-\mathrm{B} 1$ and $\mathrm{C} 3-\mathrm{B} 1$ distances are shorter. The $\mathrm{C} 1-\mathrm{B} 1$ distance is less than the $\mathrm{C} 3-\mathrm{B} 1$ distance in the case of fluoro substitution alone. However in the case of methylcyclopropane and 1,1-dimethyl cyclopropane the C3$\mathrm{B} 1$ distance is less in the TS, but in the product $\mathrm{B} 1$ gets attached to $\mathrm{C} 1$ (Markownikoff product).

The molecular orbital plots in Figure 5 of intermediate complexes and "loose" transition structures and Figure 6 of "tight" transition structures show the degradation of the C1C3 partial $\pi$-system accompanied by the bond formation.

3.1. Reaction Energies. The energies of the optimized intermediate complex (LM-CX), the "loose" transition structures (TS), and the addition product along with the product type (Markownikoff or anti-Markownikoff) are shown in Table 2. The energies (in $\mathrm{kcal} / \mathrm{mol}$ ) relative to the reactants are given in Table 2. Free energy changes; $\Delta G$ and entropy change; $\Delta S$ has also been listed.

The reactants proceed without barrier to an intermediate complex and cross over a barrier between 23.52 and $30.74 \mathrm{kcal} / \mathrm{mol}$ to form the product, which is more stable than the reactants by 35.59 to $43.39 \mathrm{kcal} / \mathrm{mol}$, depending on the substituent. The intermediate occurs at shallow minima, stabilized by 0.50 to $2.00 \mathrm{kcal} / \mathrm{mol}$ relative to the reactants.

The loose transition states in these cases all correspond to barrier comparable to the case of unsubstituted cyclopropane; the barriers are slightly lower (than for cyclopropane) in the case of fluoro, methyl, and dimethyl substitutions whereas they are slightly higher for the others and the nature of the products also differs in the two cases. It is thought that the high electronegativity of fluorine causes the carbon to which it is bonded to be more positive overall, hence facilitating the abstraction of a hydride (or hydrogen with net negative Mulliken charge), thus leading to the anti-Markownikoff product. In the case of methyl substitution steric influence of the methyl group(s) may be what causes the larger $\mathrm{BH}_{2}$ moiety to move to the less substituted carbon.

In the case of "tight" transition structure no intermediate complex has been observed. The relative energies are listed in Table 3. In comparison to the "loose" transition structures "tight" transition structures are found to have low energy barriers varying between 6.60 and $10.64 \mathrm{kcal} / \mathrm{mol}$.

Single point calculations at the DFT optimized geometries have also been carried out on all the key species studied at $\operatorname{CCSD}, \operatorname{CCSD}(\mathrm{T}), \mathrm{QCISD}(\mathrm{T}), \mathrm{MP} 2$, and MP4D levels. 


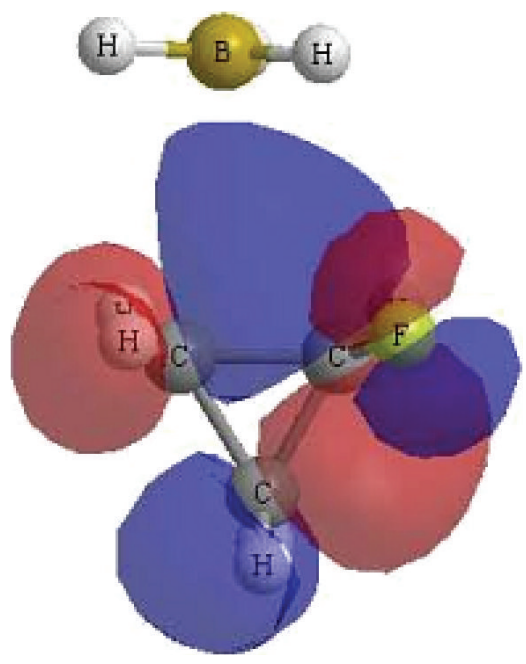

LM-CX1

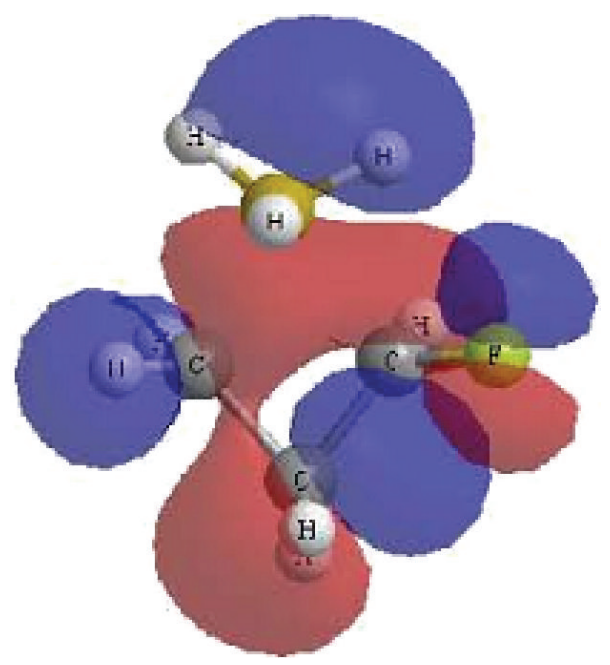

TS

FIGURE 5: HOMOs of the complexes and "loose" transition structures for the hydroboration of -F substituted cyclopropanes at B3LYP/6-31G** level along the plane of cyclopropane ring.

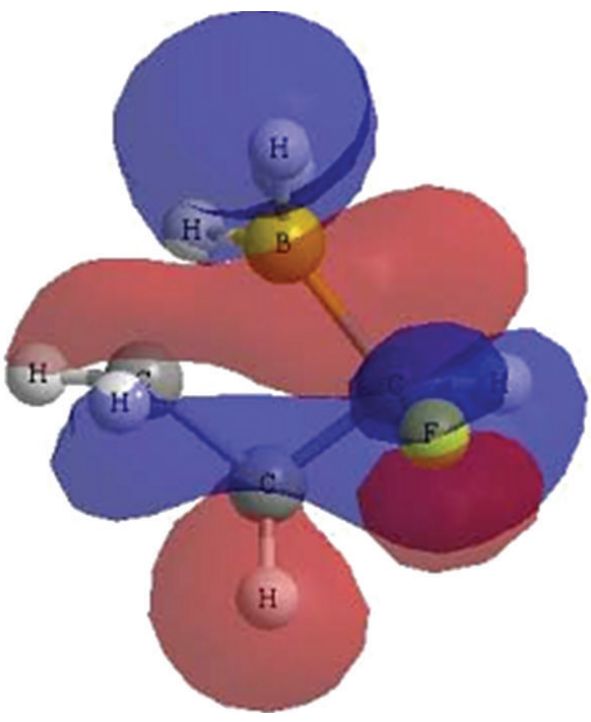

TS

FIGURE 6: HOMOs of the complexes and "tight" transition structures for the hydroboration of -F substituted cyclopropanes at B3LYP/6$31 \mathrm{G}^{* *}$ level along the plane of cyclopropane ring.

The single point energies obtained are shown in Tables S3 and S4 (Supplementary Material). It is observed that introduction of triples stabilizes the species, and the stabilization is most significant for the transition states. However one cannot conclude from this that the $\operatorname{CCSD}(\mathrm{T})$ barrier is lower than the CCSD barrier, since the points computed are not necessarily the true stationary points on the CCSD or CCSD(T) potential energy surfaces. Assuming that the true optima are not far from the DFT optima, one can say that the intermediate complexes are more stable relative to the reactants at these
post-Hartree-Fock ab initio levels than at DFT levels. However, for the transition states the situation is reversed and the transition structures have higher relative energy. The products are again at comparable relative energies to the DFT case. Since optimization at these levels is not practicable, these observations do not provide any clear pointers to the relative efficacies of these methods, and for the moment the DFT results can be taken as a good indicator of the true energy barriers.

These "tight" transition structures are an interesting anomaly in that their energies are uncharacteristically low; that is, they correspond to very low barriers compared to the other cases, being comparable to reported values for hydroboration of ethylene. The tightly bound structure being stabler is to be expected and we find that the $\mathrm{BH}_{3}$ moiety is distorted farther from planarity than in the "loose" structure. The hydrogen on the carbon atoms also assumes a nearly planar disposition.

\section{Concluding Remarks}

In summary, we have investigated the stationary structures involved in the hydroboration of substituted cyclopropanes with borane. Our study posits three-centered transition states for these reactions. It is also hoped that studies on reactions involving cyclopropane and its derivatives with other reagents will clarify the situation. Of the reactions studied three-centered transition states are encountered in the case of $\mathrm{BH}_{3}$ adding to cyclopropane with an in-plane approach. We are led to suspect that the electronic structure and high reactivity of borane are the major causative factors involved.

\section{Conflict of Interests}

The authors declare that there is no conflict of interests regarding the publication of this paper. 
TABLE 2: B3LYP/6-31G** optimized total energies (in $\mathrm{kcal} / \mathrm{mol}$ ) for the intermediate complex, "loose" transition structure, and product for substituted cyclopropanes for addition across $\mathrm{C} 1-\mathrm{C} 3$ bond along the plane of cyclopropane ring.

\begin{tabular}{lcccccc}
\hline & LM-CX & TS & Product & Product type & $\begin{array}{c}\text { Gibbs energy }\left(\Delta G_{298}\right) \\
(\mathrm{kcal} / \mathrm{mol})\end{array}$ & $\begin{array}{c}\text { Entropy change } \\
\left(\Delta S_{298}\right) \\
(\mathrm{kcal} / \mathrm{mol} \mathrm{K})\end{array}$ \\
\hline $\mathrm{C}_{3} \mathrm{H}_{5} \mathrm{~F}+\mathrm{BH}_{3}$ & -1.24 & 23.62 & -39.84 & $\mathrm{AM}$ & -34.02 & -0.008 \\
$\mathrm{C}_{3} \mathrm{H}_{5} \mathrm{Cl}+\mathrm{BH}_{3}$ & -0.58 & 28.62 & -43.39 & $\mathrm{M}$ & -36.05 & -0.014 \\
$\mathrm{C}_{3} \mathrm{H}_{5} \mathrm{CN}+\mathrm{BH}_{3}$ & -0.41 & 30.74 & -36.87 & $\mathrm{M}$ & -30.46 & -0.013 \\
$\mathrm{C}_{3} \mathrm{H}_{5} \mathrm{NC}+\mathrm{BH}_{3}$ & -0.51 & 29.65 & -36.38 & $\mathrm{M}$ & -30.13 & -0.012 \\
$\mathrm{C}_{3} \mathrm{H}_{5} \mathrm{CH}_{3}+\mathrm{BH}_{3}$ & -1.56 & 24.63 & -37.45 & $\mathrm{AM}$ & -31.78 & -0.008 \\
$\mathrm{C}_{3} \mathrm{H}_{4}\left(\mathrm{CH}_{3}\right)_{2}+\mathrm{BH}_{3}$ & -0.66 & 23.52 & -35.59 & AM & -30.28 & -0.009 \\
\hline
\end{tabular}

Relative energies for the parent cyclopropane are LM-CX $=-1.97 \mathrm{kcal} / \mathrm{mol}$, TS $=25.17 \mathrm{kcal} / \mathrm{mol}, \mathrm{LM}=-40.15 \mathrm{kcal} / \mathrm{mol}, \Delta G_{298}=-34.51 \mathrm{kcal} / \mathrm{mol}$, and $\Delta S_{298}=$ $-0.007 \mathrm{kcal} / \mathrm{mol} \mathrm{K}$.

TABLE 3: B3LYP/6-31G** optimized total energies (in kcal/mol) for the "tight" transition structure and product for substituted cyclopropanes for addition across $\mathrm{C} 1-\mathrm{C} 3$ bond along the plane of cyclopropane ring.

\begin{tabular}{lccccc}
\hline & TS & Product & Product type & $\begin{array}{c}\text { Gibbs energy }\left(\Delta G_{298}\right) \\
(\mathrm{kcal} / \mathrm{mol})\end{array}$ & $\begin{array}{c}\text { Entropy change } \\
\left(\Delta S_{298}\right) \\
(\mathrm{kcal} / \mathrm{mol} \mathrm{K})\end{array}$ \\
\hline $\mathrm{C}_{3} \mathrm{H}_{5} \mathrm{~F}+\mathrm{BH}_{3}$ & 6.60 & -36.87 & $\mathrm{M}$ & -22.90 & -0.034 \\
$\mathrm{C}_{3} \mathrm{H}_{5} \mathrm{Cl}+\mathrm{BH}_{3}$ & 9.02 & -40.65 & $\mathrm{AM}$ & -26.97 & -0.034 \\
$\mathrm{C}_{3} \mathrm{H}_{5} \mathrm{CN}+\mathrm{BH}_{3}$ & 9.26 & -37.73 & AM & -24.39 & -0.034 \\
$\mathrm{C}_{3} \mathrm{H}_{5} \mathrm{NC}+\mathrm{BH}_{3}$ & 9.75 & -38.70 & $\mathrm{AM}$ & -25.15 & -0.031 \\
$\mathrm{C}_{3} \mathrm{H}_{5} \mathrm{CH}_{3}+\mathrm{BH}_{3}$ & 8.97 & -36.16 & $\mathrm{M}$ & -22.57 & -0.035 \\
$\mathrm{C}_{3} \mathrm{H}_{4}\left(\mathrm{CH}_{3}\right)_{2}+\mathrm{BH}_{3}$ & 10.64 & -32.66 & $\mathrm{M}$ & -19.18 & -0.035 \\
\hline
\end{tabular}

\section{Acknowledgment}

One of the authors (Satya Prakash Singh) is grateful to the Ministry of Human Resources and Development (MHRD), Government of India, for the award of a fellowship.

\section{References}

[1] H. C. Brown and G. Zweifel, "Hydroboration. VII. Directive effects in the hydroboration of olefins," Journal of the American Chemical Society, vol. 82, no. 17, pp. 4708-4712, 1960.

[2] J. R. Phillips and F. G. A. Stone, "Organoboron halides. Part VI. Hydroboration of 3,3,3-trifluoropropene," Journal of the Chemical Society, pp. 94-97, 1962.

[3] G. D. Graham, S. C. Freilich, and W. N. Lipscomb, "Substituent effects in hydroboration: reaction pathways for the Markownikoff and anti-Markownikoff addition of borane to propylene and cyanoethylene," Journal of the American Chemical Society, vol. 103, no. 10, pp. 2546-2552, 1981.

[4] C. Villiers and M. Ephritikhine, "Borane-catalyzed hydroboration of substituted alkenes by lithium borohydride or sodium borohydride," Tetrahedron Letters, vol. 44, no. 44, pp. 80778079, 2003.

[5] Y. J. Xu, Y. F. Zhang, and J. Q. Li, “Theoretical study of the hydroboration reaction of disilenes with borane," Chemical Physics Letters, vol. 421, no. 1-3, pp. 36-41, 2006.

[6] S. P. Singh and P. P. Thankachan, "Theoretical study of the hydroboration reaction of cyclopropane with borane," Journal of Molecular Modeling, vol. 18, no. 2, pp. 751-754, 2012.
[7] S. P. Singh and P. P. Thankachan, "Hydroboration of cyclopropane: a transition state study," Chemical Science Transactions, vol. 2, no. 2, pp. 479-484, 2013.

[8] S. P. Singh and P. P. Thankachan, "Hydroalumination of cyclopropane: a transition state study," Chemical Science Transactions, vol. 2, no. 3, pp. 1009-1015, 2013.

[9] A. D. Becke, "Density-functional thermochemistry. III. The role of exact exchange," The Journal of Chemical Physics, vol. 98, no. 7, pp. 5648-5652, 1993.

[10] M. J. Frisch, G. W. Trucks, H. B. Schlegel et al., Gaussian 98, Revision A.7, Gaussian, Pittsburgh, Pa, USA, 1998.

[11] J. Cizek, "On the use of the cluster expansion and the technique of diagrams in calculations of correlation effects in atoms and molecules," Advances in Chemical Physics, vol. 14, pp. 35-89, 1969.

[12] G. D. Purvis and R. J. Bartlett, "A full coupled-cluster singles and doubles model: the inclusion of disconnected triples," The Journal of Chemical Physics, vol. 76, no. 4, pp. 1910-1918, 1982.

[13] G. E. Scuseria, C. L. Janssen, and H. F. Schaefer III, "An efficient reformulation of the closed-shell coupled cluster single and double excitation (CCSD) equations," Journal of Chemical Physics, vol. 89, no. 12, pp. 7382-7387, 1988.

[14] G. E. Scuseria and H. F. Schaefer III, "Is coupled cluster singles and doubles (CCSD) more computationally intensive than quadratic configuration interaction (QCISD)?” The Journal of Chemical Physics, vol. 90, no. 7, pp. 3700-3703, 1989.

[15] J. A. Pople, M. Head-Gordon, and K. Raghavachari, "Quadratic configuration interaction. A general technique for determining electron correlation energies," The Journal of Chemical Physics, vol. 87, no. 10, pp. 5968-5975, 1987. 
[16] M. Head-Gordon, J. A. Pople, and M. J. Frisch, "MP2 energy evaluation by direct methods," Chemical Physics Letters, vol. 153, no. 6, pp. 503-506, 1988.

[17] M. J. Frisch, M. Head-Gordon, and J. A. Pople, "A direct MP2 gradient method," Chemical Physics Letters, vol. 166, no. 3, pp. 275-280, 1990.

[18] M. J. Frisch, M. Head-Gordon, and J. A. Pople, "Semi-direct algorithms for the MP2 energy and gradient," Chemical Physics Letters, vol. 166, no. 3, pp. 281-289, 1990.

[19] M. Head-Gordon and T. Head-Gordon, "Analytic MP2 frequencies without fifth-order storage. Theory and application to bifurcated hydrogen bonds in the water hexamer," Chemical Physics Letters, vol. 220, no. 1-2, pp. 122-128, 1994.

[20] S. Saebo and J. Almlof, "Avoiding the integral storage bottleneck in LCAO calculation of electron correlation," Chemical Physics Letters, vol. 154, pp. 83-89, 1989.

[21] D. E. Woon and T. H. Dunning Jr., "Gaussian basis sets for use in correlated molecular calculations. III. The atoms aluminum through argon," The Journal of Chemical Physics, vol. 98, no. 2, pp. 1358-1371, 1993. 

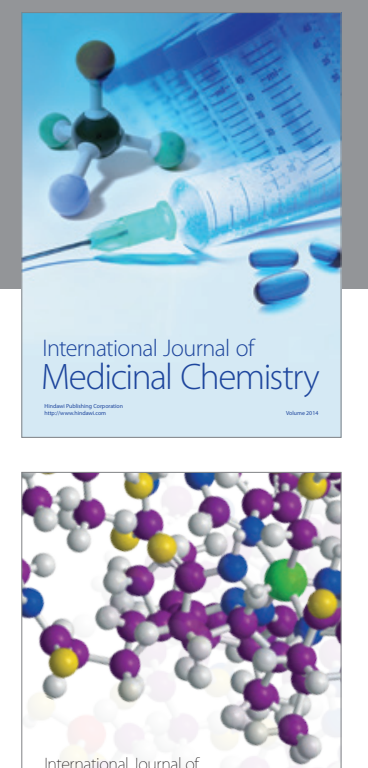

\section{Carbohydrate} Chemistry

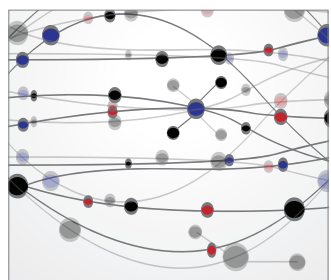

The Scientific World Journal
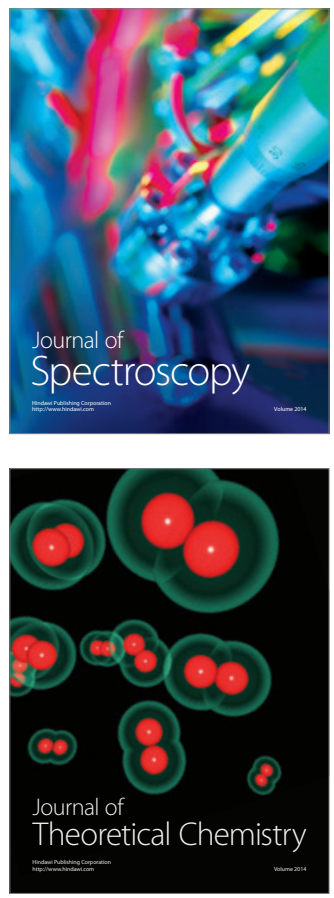
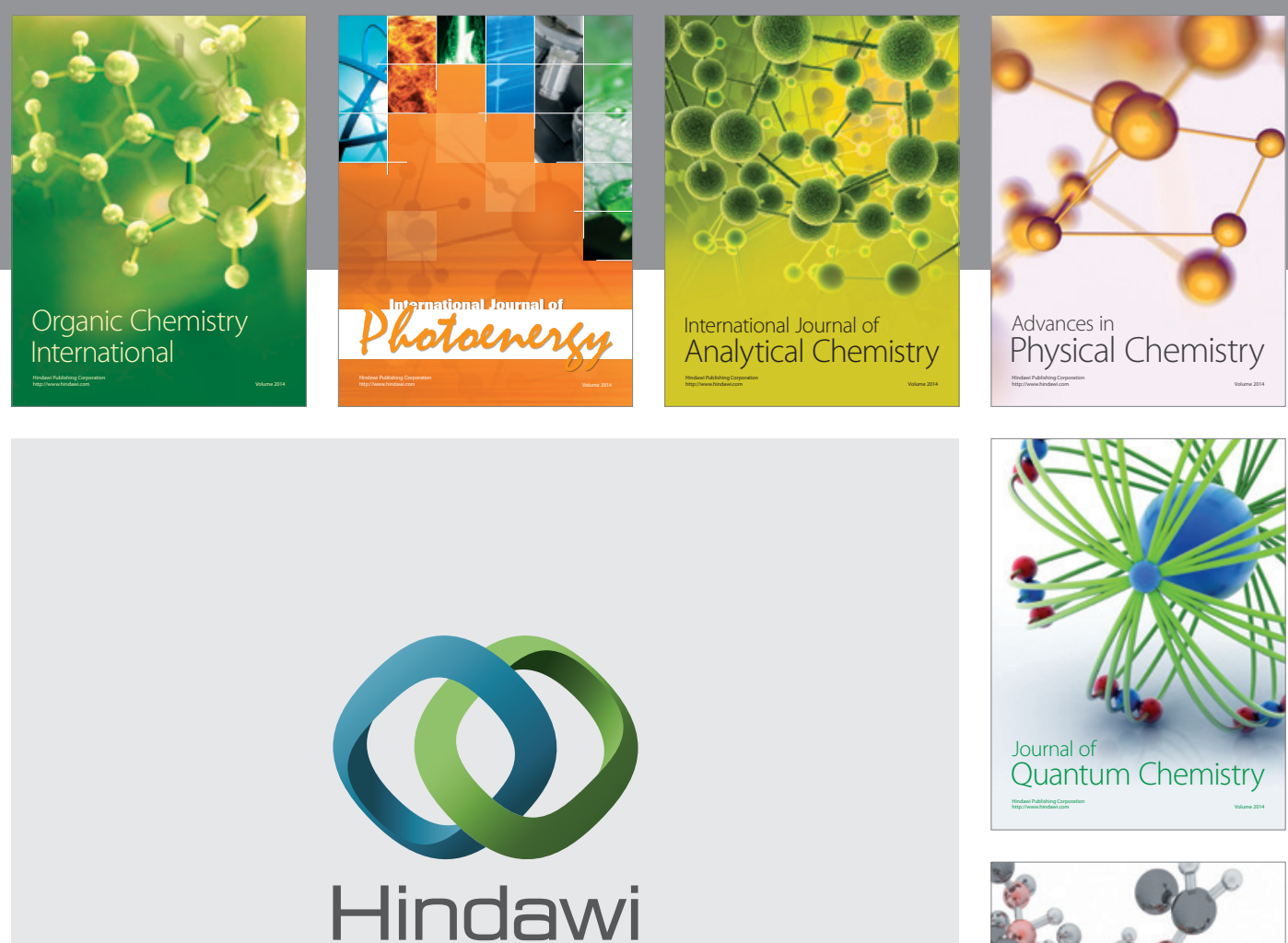

Submit your manuscripts at

http://www.hindawi.com

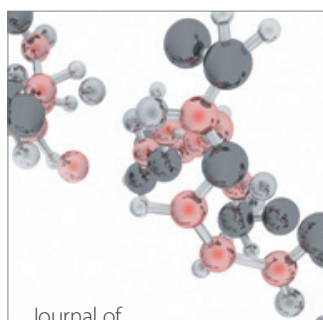

Analytical Methods

in Chemistry

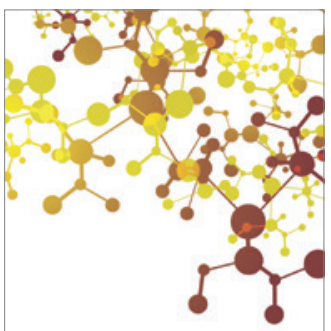

Journal of

Applied Chemistry

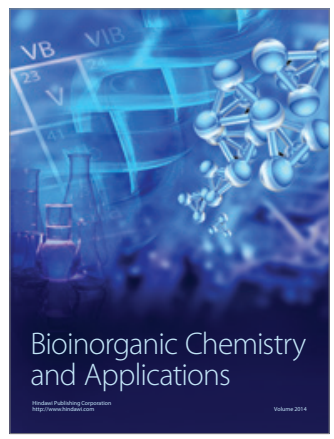

Inorganic Chemistry
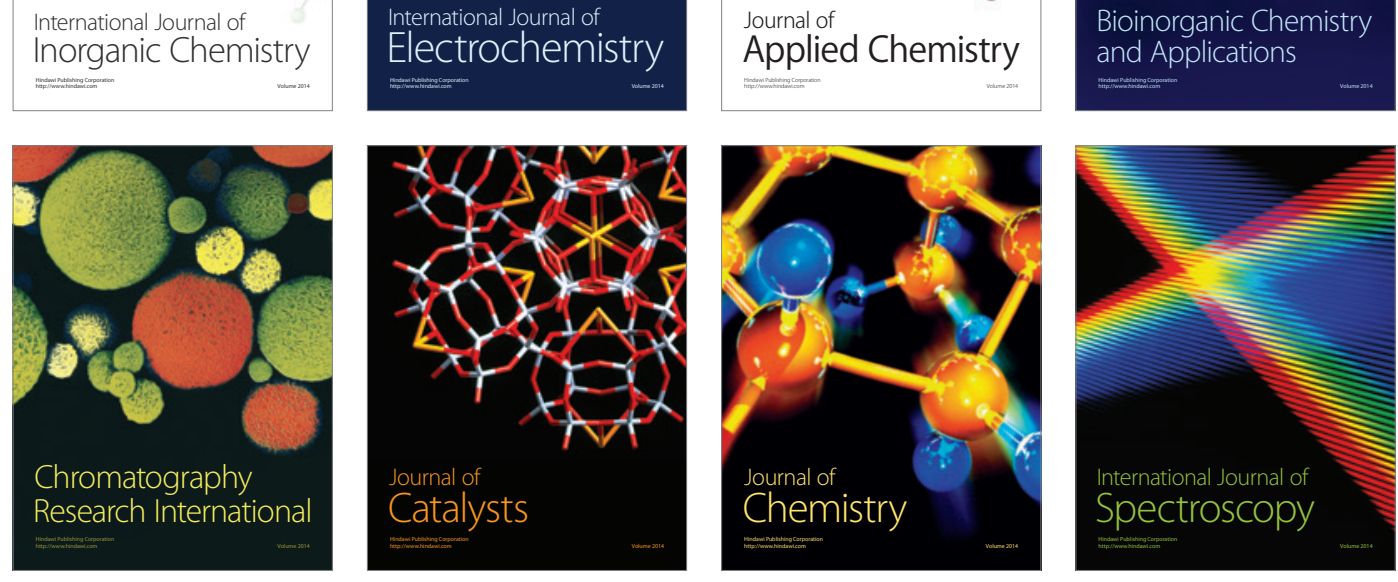